\title{
A matemática das crianças pequenas e a literatura infantil*
}

\section{Little children mathematics and literature for children}

\author{
Eloísa Zacarias** \\ Maria Lucia Faria Moro***
}

\begin{abstract}
RESUMO
O artigo descreve elaborações iniciais de matemática de crianças pré-escolares, no contexto de trabalho com literatura infantil. Estudos contemporâneos mostram a riqueza das referidas elaborações, mas são pouco numerosos os que tomam histórias infantis como contexto de iniciação matemática. Para examinar as possibilidades dessa alternativa, foi composto ao acaso um grupo de sete crianças (faixa etária: cinco anos), alunos de uma instituição particular. O grupo passou por três sessões de aprendizagem sobre noções da aritmética elementar apresentadas na forma de problemas sobre eventos da história "Branca de Neve e os Sete Anões". Propostos oralmente pela pesquisadora no papel de professor, os problemas da primeira e da segunda sessão versaram sobre adição-subtração, proporção dois para um e comparação de medidas intensivas. Na terceira sessão, as crianças foram convidadas a propor problemas sobre temas da história, além de solucionar problemas propostos pelo adulto. Todas as soluções orais e as notações interpretadas de cada criança foram registradas em vídeo e analisadas qualitativamente. Os resultados apontam para: for-
\end{abstract}

* Este artigo é parte da pesquisa realizada pela primeira autora para sua dissertação de Mestrado em Educação, defendida no Programa de Pós-Graduação em Educação do Setor de Educação da Universidade Federal do Paraná, linha de pesquisa Educação Matemática, sob a orientação da segunda autora.

** Mestre em Educação (UFPR). Coordenadora da Lúmen Educação Infantil e Ensino Fundamental (Curitiba - PR). E-mail: eloisazacarias@hotmail.com

*** Doutora em Educação (PUC-SP). Professora Titular em Psicologia da Educação e, atualmente, professor pesquisador sênior da Universidade Federal do Paraná/Programa de Pós-Graduação em Educação. E-mail: mlfmoro@sul.com.br 
mas de cálculos orais, aditivos e subtrativos, com notações correspondentes (desenhos e algarismos); comparações qualitativas de medidas intensivas e cálculo aditivo em relações proporcionais. As notações produzidas foram apoio para a expressão dos cálculos e relações elaboradas pelas crianças. É discutida a importância: das histórias infantis como contexto favorável às elaborações matemáticas na educação infantil, e como forma de integrar o trabalho em matemática ao de exploração do vocabulário e da imaginação infantis; das formas de intervenção do professor.

Palavras-chave: literatura infantil, matemática pré-escolar, iniciação matemática e histórias infantis, conceitos aritméticos iniciais.

\begin{abstract}
The paper describes the first mathematical conceptual constructions of preschoolers and how they occur on working with children's stories. Current studies show how rich are those initial concepts; however, few among them take into account children's stories as a context for mathematical initiation. In order to evaluate the possibilities of that alternative, a group of seven children (five years-old) of a private preschool was composed at random in order to take three lessons about elementary arithmetical notions, presented as problems involving events of "Snow White and the seven dwarves". Orally presented by the researcher as a teacher, problems of the first and the second sessions referred to additionsubtraction, ratio two for one and comparison of intensive measures. On the third session, the children were invited to create problems about the story issues, but they also solved problems proposed by the researcher. All the verbal solutions and the interpreted notations of each child were videotaped and qualitatively analyzed. Results point out to: forms of additive and subtractive oral calculations, with their corresponding notations (drawings and digits); qualitative comparisons of intensive measures, and additive calculations of basic proportional relations. The support provided to the children by the produced notations was predominant to their verbalization of the calculations and the elaborated relations. The discussion focuses on the relevance of: children's stories as a favorable context to mathematical elaboration of preschoolers, and as a way to integrate the mathematical initiation to the enhancing of children's vocabulary and imagination; forms of teacher's intervention.

Key-words: children's stories, preschool mathematics, mathematical initiation and children's stories, first arithmetical concepts.
\end{abstract}


Muitas são as situações que podem favorecer a iniciação matemática nas escolas de Educação Infantil. Uma delas, tratada neste texto, é o trabalho com a literatura infantil. Este se constitui em uma "prática pedagógica aberta, atual, que permite à criança conviver com uma relação não passiva entre a linguagem escrita e a falada. De algum modo a literatura aparece à criança como manifestação do sentir e do saber que permite a ela inventar, renovar e discordar". (SMOLE, 1996, p. 2).

Quase sempre, as histórias infantis são utilizadas no trabalho de linguagem oral e escrita das crianças pequenas. Por meio delas, alfabetiza-se, desenvolve-se o gosto e o prazer pela leitura e escrita de textos, amplia-se a capacidade lingüística e o vocabulário dessas crianças.

Ao oferecerem desafios de natureza cognitiva e ao traduzirem sentidos que transcendem o significado de suas palavras, os textos literários valorizam a inteligência da criança, sua capacidade interpretativa e lhe possibilitam resolver problemas cuja natureza abstrata ela é incapaz de alcançar, a não ser pela adesão ao universo simbólico. Conseqüentemente, instalam a motivação interna da criança para a leitura, visto que ela deseja ler porque a linguagem de narrativas e de poemas a mobiliza para a compreensão do mundo e para a autonomia daí decorrentes. Como experiência da festa, os textos literários invertem o processo convencional da alfabetização, pois a ênfase passa a recair sobre o significado e não sobre o significante, sobre o desejo em vez da necessidade, sobre injunções de origem pessoal que se orientam, todavia, para o atendimento de expectativas sociais. A criança conjuga, assim, à necessidade de se instituir sobre o sujeito, em sua relação com o outro, o poder de instituir novas e contínuas descobertas pelo acesso ao código escrito. (SARAIVA, 2001, p. 19).

Como muitos autores esperam que, nas escolas, trabalhe-se a literatura visando conteúdos relativos à alfabetização, poucos vêem as produções da literatura infantil como contexto possível para se trabalhar conceitos matemáticos. Porém, as histórias podem oferecer aspectos bastante oportunos para que conceitos matemáticos sejam apresentados às crianças.

Podemos admitir que, "se um material de literatura infantil usado em aulas de matemática estiver adequado às necessidades do desenvolvimento da criança, as situações-problema colocadas a ela enquanto manipula esse material fazem com que haja interesse e sentimento de desafio na busca por diferentes soluções aos problemas propostos." (SMOLE, 1996, p. 72). 
Considerando a capacidade infantil de interpretar as histórias e a necessidade de estimular essa capacidade, admitimos que as crianças podem iniciar a compreensão de vários conceitos matemáticos básicos, os que são possíveis de serem tratados por meio de problemas em torno dos temas das histórias. Ou seja, o educador infantil pode trabalhar fazendo uma conexão entre as interpretações das histórias da literatura infantil e a iniciação matemática, para incentivar as crianças a aprender novas noções matemáticas e a utilizar melhor as já aprendidas.

Assim, durante o trabalho com os livros de história, a questão interessante é a de propor problemas da aritmética elementar para as crianças irem resolvendo. E as próprias histórias podem trazer dados importantes para que alguma solução a esses problemas seja encontrada.

Também é o caso de estimular as crianças a explorar e a formular problemas para serem resolvidos por elas próprias e pelos colegas. As questões colocadas farão com que elas debatam, dialoguem, critiquem e criem diversas estratégias de solução.

Por seu lado, ao professor cabe colocar às crianças questões condizentes aos objetivos que pretende alcançar em iniciação matemática.

Já o aluno, precisa conhecer a história e se interessar por ela. "Os alunos precisam ter direito à recreação, ao prazer da leitura gratuita e ao sonho. Para isso, o professor deve lembrar sempre de deixar o livro ser manuseado, folhado, buscado, separado, revisto até que a curiosidade seja despertada." (SMOLE, 1996, p. 76).

Assim sendo, se muitas indicações existem para se provocar a aprendizagem inicial de conceitos matemáticos por meio da literatura infantil, é difícil encontrar investigações que descrevam quais são e como ocorrem, no contexto do trabalho com a literatura infantil, as elaborações iniciais de conceitos matemáticos de crianças pequenas. Para realizar esta descrição é que o estudo ora relatado foi efetuado.

\section{Método}

Para realizar o estudo, escolhemos a história infantil Branca de Neve e os Sete Anões, por ser ela, em geral, bastante conhecida pelas crianças da faixa etária escolhida. Então, os problemas de aritmética elementar aplicados foram inspirados por episódios dessa história. 
Sete crianças, da faixa etária de cinco anos, matriculadas em uma instituição particular de Educação Infantil de Curitiba, participaram da investigação. ${ }^{1}$ Elas, meninos e meninas, foram escolhidos por sorteio aleatório para compor o grupo.

Os problemas aritméticos sobre episódios da história escolhida foram apresentados ao grupo em três sessões, a saber:

- na primeira sessão, o adulto, como professor, propôs três problemas para os sujeitos tentarem resolver: um de adição de duas parcelas de pequeno valor (Branca de Neve estava arrumando a mesa para ela e os 7 anões almoçarem. Quantos pratos ela tinha que colocar na mesa?); um de subtração de parcelas de pequeno valor (Branca de Neve tinha 9 guardanapos. Tinha que dar um para cada um que ia almoçar, contando com ela. Quantos guardanapos ela teve que distribuir? Quantos sobraram na mão dela?); e um de raciocínio multiplicativo básico, de relação "um para dois". (Cada anão levava para trabalhar duas ferramentas. Quantas ferramentas os 7 anões levavam ao todo?);

- $\quad$ na segunda sessão, o adulto propôs três problemas que envolviam a comparação de medidas intensivas; por exemplo: Os sapatos da Branca de Neve são maiores ou menores do que os sapatos dos anões?

- na terceira sessão, o adulto pediu que o grupo de crianças inventasse problemas para solução pelo próprio grupo. Os problemas inventados, porém, não traziam propriamente valores numéricos e foram do gênero: Os anões se perderam na floresta quando eles estavam voltando do trabalho. Daí você tem que sair do labirinto; ou Eles perderam a mina de ouro que eles acharam. Diante desses problemas inventados, na mesma sessão o adulto apresentou outros problemas, de adição e de subtração, com valores numéricos de pequena extensão. Por exemplo: Branca de Neve estava brincando de esconde-esconde com os 7 anões e eles foram se esconder. Dos 7 anões, ela achou 4. Quantos faltavam para ela achar?.

Os problemas propostos (pelo adulto ou pelas crianças em todas as sessões) foram solucionados verbalmente de início; depois, as crianças, quando o desejavam, utilizaram o desenho como registro de algumas idéias que haviam expressado. Em todo o tempo havia à disposição das crianças os materiais seguintes: papel, canetas hidrocor e lápis de cor. suas famílias.

1 Para as crianças participarem do trabalho houve consentimento da direção da escola e de 
Todas as falas e produções escritas de todas as crianças ocorridas durante as diferentes tentativas de solução foram gravadas em vídeo e em áudio. Após a transcrição completa e revisada de todo esse conjunto de dados, foram eles analisados qualitativamente para serem identificados os diferentes tipos de solução de cada criança a cada um dos problemas aritméticos trabalhados.

\section{Resultados}

A análise qualitativa de cada solução das sete crianças participantes nos permitiu identificar diferentes tipos de soluções aos problemas, os quais passamos a descrever por sessão e conforme cada problema.

\section{Primeira Sessão}

Para o primeiro problema proposto, de adição de parcelas simples (Branca de Neve estava arrumando a mesa para ela e os 7 anões almoçarem. Quantos pratos ela tinha que colocar na mesa?), os diferentes tipos de soluções foram os seguintes:

1. Solução verbal sem apoio em notações, quando o cálculo aditivo foi efetuado:

a) com o auxílio dos dedos das mãos com justificativa também ali apoiada para acrescentar a parcela menos extensa, 1, à parcela mais extensa, 7. Por exemplo: ${ }^{2}$

Lu: "Ó! É ela e os sete anões. Sete, o anão aqui (mostra todos os dedos de uma das mãos) e a Branca de Neve aqui (mostra 2, depois mais 1 nos dedos da outra mão)... sete, oito (olhando uma e outra mão), é bem fácil.";

2 Nos exemplos apresentados, a letra $\mathrm{P}$ designa intervenção do pesquisador no papel de professor. A participação de cada criança é indicada por abreviações correspondentes à identificação de cada uma delas. 
b) sem auxílio dos dedos das mãos, com cálculo mental, sendo o total anunciado imediatamente e justificado pelo acréscimo da parcela menos extensa, 1 , à parcela mais extensa 7. Por exemplo:

P: "E aí, Fe, quantos pratos tem que colocar na mesa?". Fe: "Oito.”; P: "Por que oito, Fe?"; Fe: "Porque tem mais ela (Branca de Neve)."; P: “Ah!... por que tem mais ela? Ela e quem mais?"; Fe: "E os sete anões."

2. Solução verbal com apoio em notações, quando o cálculo aditivo ocorreu a partir de desenhos dos elementos dos problemas, realizados imediatamente antes, sendo:

a) cálculo aditivo do total, com base no desenho direto do resultado da adição, justificado pela adição implícita de um elemento aos da parcela mais extensa. Por exemplo:

Fi (para desenho de 8 pratos): "Eu desenhei os pratos."; P: "Quantos pratos você desenhou?"; Fi: Oito.”; P: "Por que oito?"; Fi: “Oito com a Branca de Neve.";

b) cálculo aditivo do total, com base na escrita direta de algarismos conforme a seqüência convencional, cada um deles representado como denominador de cada elemento das parcelas da adição, estas já totalizadas. Assim, para resultado aditivo 8, a criança escreveu: 1 2345678 , indicando cada algarismo ao dar a resposta da adição;

c) cálculo aditivo do total sem relação da expressão oral da solução com a expressão notacional: a criança realiza verbalmente o cálculo do total dos elementos existentes; porém, o desenho (antes produzido) dos elementos ultrapassa o total verbalizado sem que a criança perceba esse fato. Por exemplo:

P: "E você, Fe? Eu só estou vendo três pratos por enquanto.”; Fe: "É porque eu emprestei minha caneta."; P: "Então pegue outra canetinha, ó... (P entrega caneta para $\mathrm{Fe}$ )... então quantas você já fez, Fe?"; F: "Três, quatro...(...) (enquanto desenha...) Fe: Quatro, cinco, seis, sete, oito." (para cada desenho de personagem indicando um nome de numeral... ). 
O segundo problema proposto foi o de adição com acréscimo da parcela menor à parcela maior e, depois, com a subtração de parcela de pequena extensão do total obtido (Branca de Neve tinha 9 guardanapos. Tinha que dar um para cada um que ia almoçar, contando com ela. Quantos guardanapos ela teve que distribuir? Quantos sobraram na mão dela?). Ele foi resolvido pelas crianças em dois momentos, o da adição e o da subtração.

Os diferentes tipos de solução para a parte aditiva (... quantos guardanapos distribuir ao todo para as pessoas que iam almoçar?) foram:

1. Solução verbal sem apoio em notações, quando o cálculo aditivo foi efetuado:

a) de imediato, com o cálculo mental das parcelas 7 (anões) e 1 (Branca de Neve). Por exemplo:

P: "Muito bem. Então, agora eu vou falar outra coisa. Ainda arrumando a mesa a Branca de Neve, ela tinha nove guardanapos para colocar na mesa, ela tinha que dar um guardanapo para cada um que ia almoçar. Quantos guardanapos ela vai distribuir?”; Bru: “Oito.”; Lu: “Oito.”;

b) com oscilações, sendo a resposta aditiva final obtida com a intervenção de rememoração da pesquisadora sobre dado total de referência (8 personagens), após resposta incorreta formulada ao pedido de justificativa, esta não expressa. Por exemplo:

Pi: (para 7+1...) "oito.”; P: "Por que oito, Pi?"; Pi: “Nove.”; P: “Quantas pessoas iam almoçar?"; Pi: "Oito.”; P; “Oito? Então, quantos guardanapos ela teve que distribuir?; Pi: "Oito..." (junto...) Lu: "Oito."

Vemos que os dois tipos de solução recém descritos têm em comum o fato de serem verbais e, como diferença, o fato de ter sido a solução obtida com a intervenção da pesquisadora.

2. Solução verbal com apoio em notações, com cálculo aditivo apoiado na correspondência termo a termo entre elementos. Trata-se da única forma de solução com notação observada e traz o desenho de duas coleções de elementos (uma para guardanapos e outra para pratos) pareados um a 
um, realizado com intervenção da pesquisadora, e após a rememoração da parcela mais extensa, 7 , e da menos extensa, 1. Por exemplo:

P (diante de desenho de guardanapos de Fe): "O que você está desenhando? Os guardanapos? Quantos guardanapos você desenhou?"; Fe: "Nove.”; P: "Nove?"; Fe: "É."; P: "Quantos que ela distribuiu na mesa?"; Fe: "Nove.”; P: "Nove? Quantas pessoas eram para almoçar?... Lembra aqui os pratos que você desenhou (apontando desenhos ...) Vamos contar: um, dois, três, quatro, cinco, seis, sete... (junto com Fe, que aponta os 7 pratos que desenhou)... quantas pessoas iam almoçar, você lembra?"; Fe: "Faltou um (desenha mais 1 prato)."; P: "Ah!...faltou um? O que aconteceu aí?"; Fe: "Sete, oito." (apontando últimos desenhos); P: "Agora, você vai colocar um guardanapo para cada prato. Quantos guardanapos são, será?; Fe: “Oito.”(faz desenhos de 8 guardanapos pareados aos dos pratos).

Os tipos de solução para a parte subtrativa do problema foram os seguintes:

1. Solução verbal sem apoio em notações:

a) com cálculo subtrativo mental, imediato, mas com justificativa apoiada na contagem unitária dos dedos das mãos de elementos a subtrair, após identificação da parcela mais extensa. Por exemplo:

P: “E quantos vão sobrar na mão dela?”; Bru: “Um.”; Lu: “Um.”; P: "Por que um?"; Bru: "Oito menos nove,... nove menos um, daria um... não! É..., oito menos um daria um... não! Espera aí!"; P: "Ela tem nove guardanapos na mão."; Bru: "Sobraria só um. Só um.”; P: "Como?"; Bru: "Olha...(estica 9 dedos) aqui tem nove, ó..."; P (para o grupo): "Prestem atenção, o Bru está explicando."; Bru: "Nove guardanapos (ainda esticando os 9 dedos)... daí ela deu um para este (abaixa 1 dedo)... um para este (abaixa outro dedo), outro para outro anão, outro para outro anão... (vai abaixando dedos, um a um, até contar 7 anões)... e outro para ela (abaixando mais um dedo, ao todo 8 dedos)... então sobrou um, daí..." (1 dedo esticado); 
b) com cálculo subtrativo mental, apoiado na adição do resultado final ao elemento restante, ou seja, indicando as sobras: 1 guardanapo para Branca de Neve e outro que sobrou na mão dela, fazendo a adição $1+1$. Por exemplo:

Fi: "Sobraram dois na mão dela."; P: "Na mão dela? Por que Fi?"; Fi: "Um para ela, e um, mais um que sobrou."

2. Solução verbal com apoio em notações, quando as soluções subtrativas observadas têm em comum o fato de as crianças terem utilizado, como apoio, as notações realizadas para a solução do primeiro problema. Exemplificamos, a seguir, uma solução subtrativa típica, sem justificativa, com cálculo apoiado nos algarismos da notação antes produzida. Esta, por seu lado, é então complementada com desenhos dos elementos correspondentes (para cada algarismo de 1 a 8 um guardanapo até 8 , conforme Figura 1). No entanto, há a intervenção da pesquisadora para a sobra ser identificada:

\begin{abstract}
Ra (ergue a folha para todos verem o que marcou, um guardanapo para cada algarismo); P: "Você colocou um guardanapo ao lado de cada número? É isso que você fez?; Ra: "É."; P: "Quantos guardanapos você desenhou?"; Ra: "Oito.”; P: "E aonde está o guardanapo que sobrou na mão dela?"; Ra: "Vou desenhar."; P: "Aonde você vai desenhar o guardanapo que sobrou?"; Ra: “Aqui...” (apontando para canto da folha e desenha 1 guardanapo).
\end{abstract}

Esse tipo de solução somente foi justificado quando as crianças apoiaram-se no desenho de elementos em correspondência termo a termo, correspondência esta feita conforme os valores das parcelas do problema, identificando o elemento restante então desenhado.

Para o terceiro problema proposto na primeira sessão (Cada anão levava para trabalhar duas ferramentas. Quantas ferramentas os 7 anões levavam ao todo?), um problema de proporção "um para dois" do quadro das estruturas multiplicativas, conforme Vergnaud (apud FRANCHI, 1999), as soluções das crianças foram sempre apoiadas em notações. Mas algumas foram produzidas sem a intervenção da pesquisadora; outras, com esta intervenção.

O tipo de solução encontrado consistiu em variações, como soluções corretas e incorretas, da representação em desenho, de elementos envolvidos segundo a relação "para cada um, dois...", com contagem unitária do total 


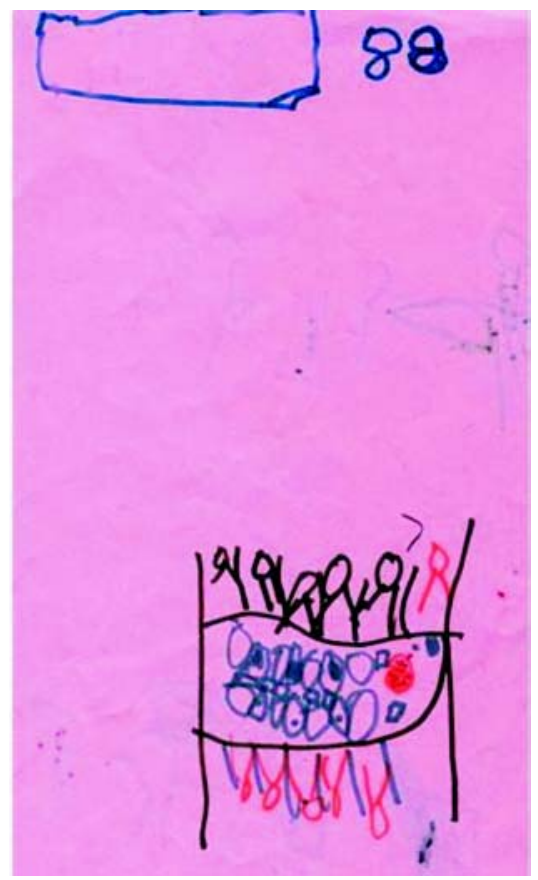

obtido para chegar à resposta (Figura 2). Por vezes, esse total estava incompleto, como vemos a seguir:

Fe (depois de desenhar 2 ferramentas para cada um de 6 anões, conta as ferramentas desenhadas e escreve algarismos conforme seqüência, até 12, embaixo de cada ferramenta); P: "São doze ferramentas que eles levam ao todo?"; Fe: "Sim."; P: "Como você fez? Você conta para mim? Eu preciso saber."; $\mathrm{Fe}$ (apontando cada desenho): "Um, dois, três, quatro, cinco, seis, sete, oito, nove, dez, onze, doze.”; P; “Tá. Mas cada anão levava para trabalhar duas ferramentas, não é? Como é que você fez isso?"; Fe: "Fazendo bolinhas."; P; Fazendo bolinhas? Então tá bom..." (como a criança mostrava sinais de cansaço, a pesquisadora não mais insistiu na busca de outra resposta). 


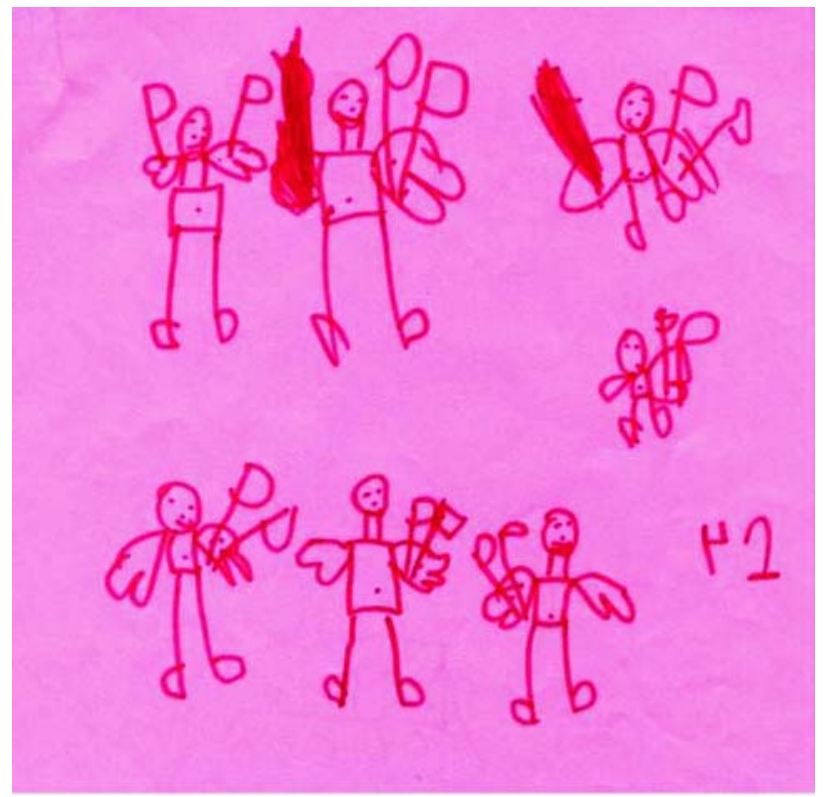

Outras crianças desenharam ferramentas em excesso. Acreditando que elas poderiam chegar ao resultado correto, a pesquisadora realizou algumas intervenções. Algumas das crianças fizeram então cálculo subtrativo ao perceber que haviam desenhado 4 ferramentas para 1 anão ao invés de 2 , e se serviram da contagem unitária dos elementos para verificar suas soluções. Eis um exemplo:

Pi (para desenho de 16 ferramentas, 2 delas para um só anão): “É... (e apontando cada desenho)... um, dois, três, quatro, cinco, seis, sete, oito, nove, dez, onze, doze, treze, quatorze, quinze, dezesseis."; P: "Dezesseis? Quantos anões você desenhou?"; Pi: "Sete."; P; "Vamos contar?"; Pi (aponta desenhos dos anões): "Um, dois, três, quatro, cinco, seis, sete. Sete."; P: "Vamos ver uma coisa? Cadê as ferramentas deste anão?" (aponta primeiro desenho de anão); Pi: "Tá aqui" (aponta desenho de 2 ferramentas ao lado do desenho do anão); P; "E estas ferramentas?" (aponta 4 ferramentas desenhadas para o último anão); Pi (riscando 2 
ferramentas que sobraram); P; "O que você está fazendo?"; Pi:“Tirando essa ferramenta porque ele tinha duas.”; $\mathrm{P}$ : “Ah! Tinha duas? Ou quantas ele tinha?"; Pi: "Ele tinha uma, duas três, quatro..." (apontando 4 ferramentas desenhadas para o anão); P: "Ah! Ele tinha quatro. Tem que ser duas, né? Então agora conte..., vamos ver se você consegue.”; Pi (apontando cada desenho de ferramenta): "Uma, duas, três, quatro, cinco, seis, sete, oito, nove, dez, onze, doze, treze, quatorze."

\section{Segunda Sessão}

Para o primeiro problema proposto na segunda sessão, o de comparações qualitativas com medidas intensivas (Qual a altura da Branca de Neve em relação aos anões?), as soluções encontradas foram todas de comparações qualitativas com medidas intensivas. Foram soluções que as crianças aplicaram, tendo como base o significado dos termos comparativos para comparações qualitativas. Eis os termos empregados adequadamente: maior, muito maior, menor, mais baixa, mais alta. Por exemplo:

A pesquisadora sentou ao lado do Fe e observou seu desenho. Tinha feito dois desenhos de pessoas, um bem maior que o outro (Figura 3). P: "Quem que é menor aí?"; Fe: "O Dunga.”; P: “O Dunga? É este aqui que você está desenhando?" (apontando para o desenho menor); Fe: "É.”; P: "E esse aqui?" (apontando para o maior); Fe: "Branca de Neve."; P: "Esse aqui o que que é?" (apontando para o maior); Pi: "É a Branca de Neve."; P: "E esse aqui?" (apontando para o menor); Pi: "O anão."

Para o segundo problema proposto, o de comparações qualitativas com medidas intensivas e proporcionalidade (Os sapatos da Branca de Neve são maiores ou menores do que os sapatos dos anões?), o único tipo de solução encontrado consistiu de comparações qualitativas com medidas intensivas e proporcionalidade, tendo também como base o significado dos termos comparativos empregados adequadamente, tais como: maior, menor, muito, pouco. Por exemplo: 


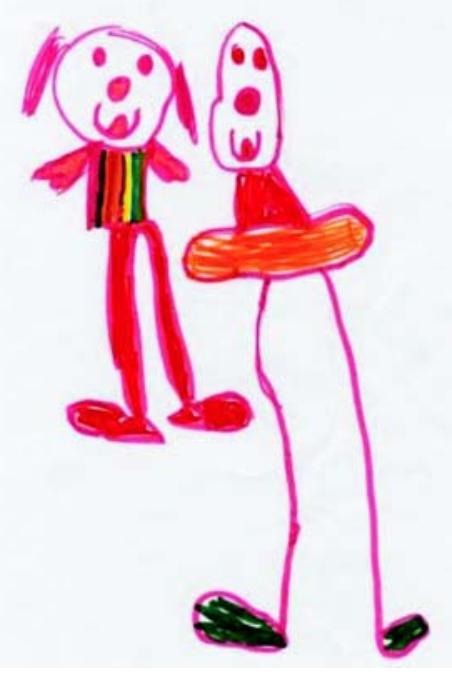

P: "Vou te ajudar. Você acha que o pé da Branca de Neve, que os sapatos da Branca de Neve são maiores ou menores que os sapatos dos sete anões?"; Pi: "Maior."; P: “Maior por quê?"; Pi: "Porque ela é mais alta e por causa que os sete anões são mais baixos."

Para o terceiro problema proposto na segunda sessão, também de comparações qualitativas com medidas intensivas (Será que todos os anões calçam o mesmo número? Por quê?), novamente o único tipo de solução encontrado envolveu comparações qualitativas com medidas intensivas, baseadas no significado de termos comparativos (maior, muito, mesmo tamanho). Por exemplo (Figura 4):

P: "Mas o sapato dele é maior ou menor que o dos outros?"; Ra: "Maior."; Lu: "Maior."; Bru: "Menor... do mesmo tamanho."; P: "Do mesmo tamanho? Todos têm do mesmo tamanho?"; Bru: "É. Todos, todos, todos, todinho." 


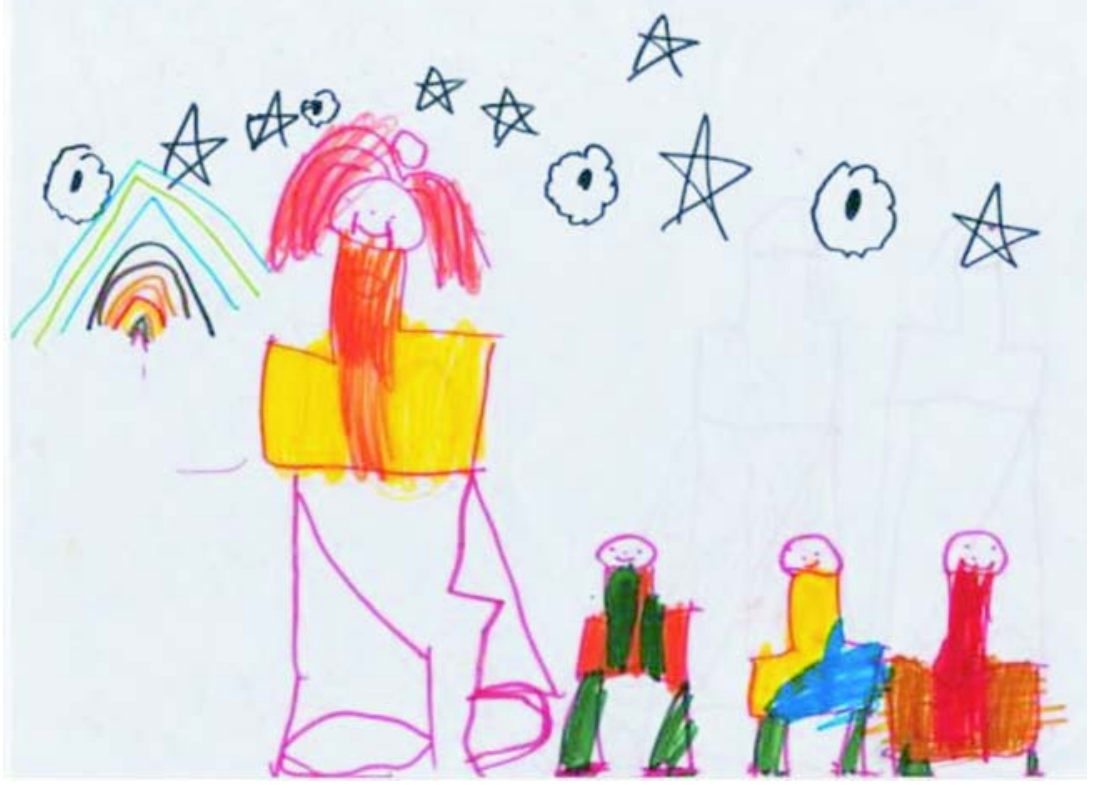

A notar que as crianças resolveram os referidos problemas de comparação de tamanho dos sapatos em relação à altura dos personagens, realizando significativamente comparações qualitativas com termos que correspondem a medidas intensivas. Por exemplo, à pergunta sobre serem os sapatos da Branca de Neve maiores ou menores que os sapatos dos anões, as crianças justificaram pela diferença de altura dos personagens: se a Branca de Neve é maior do que os anões, ela tem pé maior do que eles, então tem que ter sapato maior. Assim, apoiaram também essas comparações no esquema de correspondência termo a termo entre elementos de medidas intensivas equivalentes: altura maior de Branca de Neve, sapato maior para ela; altura menor dos anões, sapato menor para eles.

\section{Terceira Sessão}

Quando, nessa sessão, as crianças foram estimuladas a formular problemas para os colegas resolverem, as soluções por elas apresentadas foram, de início, verbais para depois utilizar o desenho como registro de algumas idéias que antes haviam expressado. 
As crianças propuseram diferentes problemas relativos ao tema da história, apontando situações que necessitavam de solução. Porém, os problemas e, então, das soluções possíveis não continham quantidades numéricas, não dando oportunidade a cálculos aritméticos. Eis alguns dos problemas por elas inventados:

- $\quad$ Os anões se perderam na floresta:

Bru: "Os anões se perderam na floresta quando eles estavam voltando do trabalho. Daí você tem que sair do labirinto."; P: "Uh! Tinha um labirinto?"; Bru: "Do trabalho até a casa deles."; P: "Mas vamos pensar em um problema que a gente consiga resolver, né? A gente tem um labirinto aqui que a gente consiga resolver?"; Bru: "Mas a gente desenha."; P: "Ah! A gente desenha? Então, a gente pode desenhar. Então, depois a gente pode desenhar."

- Os anões se esconderam atrás do armário e não conseguiam sair:

Ra: "Todos estavam correndo. A Branca de neve tinha que pegar. Os anões se esconderam na cozinha e não sabiam como sair; daí eles se esconderam atrás do armário e não conseguiam sair.”; P (para todos): "Ah! Como eles vão sair de trás do armário? Como será que eles vão sair de trás do armário?"; Bru: "Eles empurram, eles empurram o armário e fica uma abertura mais grossa e sai. Faz de conta que esse é o armário (aponta o armário da sala)... eu ia empurrar, daí ia ficar mais grossa e ia sair."

Como as crianças não propuseram problemas envolvendo valores numéricos, para incentivá-las a fazê-lo a pesquisadora apresentou o seguinte problema de subtração com quantidades numéricas pequenas: Branca de Neve estava brincando de esconde-esconde com os 7 anões e eles foram se esconder. Dos 7 anões, ela achou 4. Quantos faltavam para ela achar?

Como tipo de solução foi então identificada a solução verbal, com cálculo efetuado com o auxílio dos dedos da mão, para encontrar aditivamente a diferença a completar entre a quantidade presente (subtraendo) e o total, como também para justificar aquela diferença. Eis dois exemplos: 
Bru: “Três.”; Ra: "Seis.”; P: "Por que seis, Ra?"; Ra: "Porque assim (estica 5 dedos) e daí vem o sete..." (estica outros 2 dedos de outra mão); Bru: "Não! Ela tinha achado quatro." (...) Bru: "Ela achou quatro, ó..." (estica 4 dedos), daí um, dois, três (estica mais 3 dedos da outra mão); P: "Quantos que têm aí agora."; Bru: "Sete."

Pi: "Sete.”; P: "E você, Pi?"; Pi: "É três porque ela achou quatro. É... quatro (apontando dedos)...cinco, seis, sete.”; Fe: “Oito.”; Pi: Não! Ela (Branca de Neve) já achou quatro; um, dois, três...” (esticando dedos); P: "Por que três?"; Pi: "Porque ela já achou quatro, daí fica três. Daí vai ficar sete.”; P: Por quê? Quatro mais três é quanto?”; Pi: Sete."

Também houve cálculo incorreto do resultado sem justificativa: a criança não soube explicar sua solução por mais que a pesquisadora tivesse insistido em sua intervenção. Por exemplo:

Fe: "Seis."; P: "Sete. E você, Fe? Por que você acha que é cinco?"; Fe: "Porque eu acho.”; P: "Então... mas explique pra gente.”; Fe: "Porque faltou quatro anões."; P: "Não... ela já achou quatro anões. Quantos que faltam para ela achar?"; Fe: “Oito.”; P: "Por que oito?”; Fe: "Porque eu não sabia."; P: "Por que você acha que é oito? Você sabe explicar por quê?"; Fe: "Não."

Adiante na sessão, a novo convite da pesquisadora, as crianças inventaram o seguinte problema subtrativo com grandezas pequenas: Branca de Neve achou 2 anões. Quantos que faltavam ela achar?

Fe: "Os anões tavam... ela só achou um anão.”; P: "Ela só achou um anão? E qual é a tua pergunta?"; Fe: "Os outros se perderam."; P: "Os outros se perderam? Então ela achou só um e os outros se perderam? Quantos que faltam ela achar? É isso?”; Fe: "Dois.”; P: “Ah! Ela achou dois?"; Fe: "É... ela achou dois".; P: "Ela achou 2. Quantos que faltam ela achar?" 
Para esse problema todas as soluções foram verbais. Mas as diferenças encontradas permitiram identificar-lhes os tipos seguintes:

1. resposta direta qualquer, incorreta, sem justificativa. Por exemplo:

Fe: "Nove, oito.”; P: Por que oito?"; Fe: "Porque eu sei...";

2. resposta com cálculo aditivo incorreto do total com a grandeza a subtrair e/ou desta grandeza com outra qualquer, com apoio em contagem (dedos). Por exemplo:

Ra: "Dois mais sete é quatro (estica 2 dedos da mão direita e 2 da mão esquerda).”; P: "Dois mais sete é quatro? Ela já achou dois. Quantos anões são?"; Ra: Dois (estica 2 dedos de uma das mãos)... daí são sete (esticando 2 dedos da outra mão)... um dois três, quatro (aponta 4 dedos esticados);

3. resposta com cálculo subtrativo, incorreta e/ou correta, com justificativa que aponta aditivamente a diferença a completar entre a quantidade presente (subtraendo) e o total, por vezes com apoio na contagem (dedos). Eis alguns exemplos:

Pi: "Seis, seis.”; P: "Seis? Porque seis, Pi?"; Fe: “Seis.”; P: "Seis também? Por quê?"; Bru: "Por quê? Deixa eu ver."; P: "Espera aí, Bru, deixa o Pi explicar."; Pi: "Porque ela achou ... quantos mesmo?"; P: "Dois.”; Bru: "Eu disse pra ele."; Pi: "Falta quatro, falta três..."; Bru: "Não. Deixa eu ver."; Pi: "Falta três, daí quatro, daí cinco, daí seis, daí fica .... depois, sete. Então falta seis pra achar porque depois do seis vem o sete, né?". Bru: "É cinco porque dois mais cinco daria sete. Quer ver? Ó... um, dois, três, quatro, cinco (estica 5 dedos de uma mão e 2 da outra)... um dois, três, quatro, cinco, seis, sete." (apontando todos os dedos).

A respeito do decorrido na terceira sessão, vimos que, ao primeiro convite, as crianças não consideraram necessariamente "problema" algo que deveria ter números e ser resolvido aritmeticamente. Pensaram, sim, em situação referente ao tema da história, mas que precisava ter alguma solução, não necessariamente aritmética. Talvez, se a pesquisadora tivesse alertado, no início, que os problemas deveriam ter números, as crianças teriam proposto problemas com dados numéricos. 
Depois que a pesquisadora propôs um problema envolvendo quantidades numéricas, as crianças seguiram o modelo fornecido e elaboraram outro problema de subtração semelhante ao da pesquisadora.

Ao final dessa sessão houve o convite da pesquisadora para que as crianças produzissem notações sobre o ocorrido. Todas as crianças, então, fizeram desenhos, os quais foram relativos a qualquer dos problemas não aritméticos que haviam inventado. Esse fato pode indicar o quanto esse tipo de realização lhes foi, de algum modo, marcante.

\section{Discussão e considerações finais}

Conforme anunciado anteriormente, o objetivo do nosso estudo foi o de descrever quais são e como ocorrem, no contexto do trabalho com a literatura infantil, as elaborações que crianças de cinco anos, aproximadamente, podem fazer de certas noções matemáticas básicas.

Em síntese, obtivemos como resultado que, naquele contexto, as crianças podem resolver problemas com adições e subtrações de parcelas simples, com correspondência termo-a-termo, com comparações qualitativas como medidas intensivas e com relação proporcional um para dois (correspondência um para dois), relação esta do quadro das multiplicações.

Entretanto, vimos que se a maioria das crianças resolveu os problemas propostos com certa facilidade, houve algumas que o fizeram com alguma dificuldade.

No que diz respeito à operação de adição, encontramos que a maioria das crianças do estudo contava os elementos de cada parcela dos problemas propostos. Nunes e Bryant (1997) explicitam que a soma das partes é uma extensão direta da contagem e isso realmente foi percebido no estudo. Foi caso exemplar o de uma criança que somou a parcela 1 (da Branca de Neve) com a parcela 7 (dos anões) para chegar ao total 8.

O problema de subtração, apresentado no estudo, consistiu em uma situação de transformação de uma quantidade total, retirando-se dela elementos. Nunes e Bryant (1997) relatam que as crianças realmente consideram mais fácil entender a idéia de subtração no contexto de problemas em que uma transformação desse tipo está envolvida.

Os problemas de adição-subtração trabalhados pelas crianças envolviam valores que estavam relacionados a elementos da história e, por isso, de- 
vem ter tido especial sentido para as crianças. Nunes e Bryant (1997) defendem este aspecto e, na pesquisa, pudemos perceber que as crianças, de fato, mostraram-se envolvidas com os problemas propostos, contando e recontando as personagens, os objetos (guardanapos, ferramentas) referidos nos problemas, mostrando que esses elementos tinham sentido para elas.

Resultados como os que obtivemos mostraram também que crianças como as examinadas podem ter domínio da contagem. Elas também já admitem, ao menos, que a função dos números seria a de designar os elementos em certa ordem para dali anunciar certa quantidade. Por exemplo, em uma clara expressão de que com cada algarismo estariam designando ou denominando cada elemento na ordem, a cada anão da história que desenhavam na solução dos problemas muitas crianças atribuíram um algarismo, contando e respeitando a seqüência numérica. Também assim fizeram, no momento de contar os guardanapos ou ferramentas que os anões, juntos, levavam para trabalhar.

A situação de correspondência um para dois (para cada anão duas ferramentas) é classificada na literatura (VERGNAUD, apud FRANCHI, 1999; NUNES; BRYANT, 1997) como uma situação multiplicativa porque envolve a idéia de proporção e a de fator escalar.

Os resultados da pesquisa mostraram que as crianças foram capazes de realizar com sucesso a correspondência um para dois com apoio em notações, porém, contando unidade a unidade (cada ferramenta) para chegar ao resultado. Elas mostraram não dispor ainda de esquemas e/ou relações suficientes para fazer adições de parcelas iguais (no caso, 2) e, muito menos, multiplicar mediante a descoberta do fator escalar envolvido (no caso, 7).

Porém, sabemos que o fato de as crianças realizarem a correspondência um para dois consiste num primeiro passo para que, adiante, consigam realizar esta adição das parcelas iguais e, mais, a multiplicação pelo fator escalar. A considerar que Rêgo e Silva (2003) constataram que, com histórias infantis, crianças da $2^{\mathrm{a}}$. série do ensino fundamental podem realizar uma construção significativa do conceito de multiplicação, dentre outros conceitos.

Com relação às comparações qualitativas como medidas intensivas, expressas nas soluções das crianças, Nunes e Bryant (1997) dizem que, primeiro, as crianças precisam saber o que os termos comparativos significam para poderem aprender os números. Por outro lado, consideram os mesmos autores, ainda que saibam o que significam termos como mais e menos, muitas crianças de cinco a seis anos não conseguem ainda utilizar este conhecimento para apontar diferenças quantitativas entre coleções. Mas, como vi- 
mos, crianças dessa faixa etária ainda muito se confundem ao utilizar os termos maior e menor, embora a maioria delas consiga expressar a diferença qualitativa em jogo colocando maior ênfase na dimensão referida. Por exemplo: Branca de Neve é muito maior que os anões.

A literatura (SMOLE, 1996; CAREY, 1992; KLIMAN, 1993, e.g.) também aponta que as crianças podem propor problemas matemáticos usando aspectos da literatura infantil.

Por essa razão, tendo também como referência resultados de um primeiro e de um segundo estudo piloto efetuados para melhor planejar nossa pesquisa, abrimos espaço no estudo principal para que as crianças formulassem problemas para que o grupo os resolvesse. Porém, ao contrário do esperado, elas não o fizeram.

Como dissemos, parece que não ficou claro, no pedido da pesquisadora, que ela esperava das crianças problemas com cálculos aritméticos. Assim sendo, as crianças formularam problemas do dia-a-dia, possíveis de serem enfrentados pelas personagens (as ferramentas quebraram, os anões se perderam na floresta, os anões se esconderam atrás do armário e não conseguiam sair). Talvez devêssemos mesmo ter pedido para que elas formulassem problemas envolvendo aquele tipo de cálculo. Ocorre que, mesmo dando um exemplo (Branca de Neve estava brincando de esconde-esconde com os 7 anões e eles foram se esconder. Dos 7 anões, ela achou 4. Quantos faltaram para ela achar?), elas só formularam um problema envolvendo cálculos e, ainda, bem semelhante ao fornecido pela pesquisadora (Branca de Neve achou 2 anões. Quantos que faltavam ela achar?).

Entretanto, é importante considerar que as crianças estudadas sabiam bem o significado do que seria um problema a resolver, tanto que formularam muitos, alguns deles, talvez, passíveis de solução, não aritmética, mas topológica (por exemplo, como sair de um espaço estreito; como deveria ser então o espaço: mais largo, muito mais largo, conforme cada anão).

Assim, nem todas as crianças da faixa etária considerada podem formular problemas matemáticos envolvendo valores numéricos, diante de um pedido como o formulado em nosso estudo. Podemos considerar que as crianças examinadas em nossos estudos anteriores formularam tal tipo de problema porque teriam um conhecimento prévio mais amplo de questões aritméticas elementares do que o das crianças do estudo principal, como também já estariam mais habituadas a trabalhar com problemas envolvendo quantidades numéricas.

As notações produzidas pelas crianças apoiaram muito suas soluções, principalmente as do terceiro problema da primeira sessão, o problema de 
caráter multiplicativo (Cada anão levava para trabalhar 2 ferramentas. Quantas ferramentas os 7 anões levavam ao todo?). Todas as crianças, sem exceção, realizaram suas soluções utilizando-se das notações que foram feitas, os desenhos dos personagens e os objetos dos problemas e a escrita dos algarismos.

Os estudos sobre notações de Selva e Brandão (2000) vão ao encontro do que foi obtido nesta pesquisa. Essas autoras consideram que o registro escrito apóia os cálculos realizados, possibilitando a reorganização do processo de raciocínio e favorecendo o avanço no registro das operações.

Podemos levar em conta, então, que os registros no papel são, não só facilitadores das explicações das crianças, mas também apoio para o desenvolvimento de estratégias com números maiores que 10 , fato constatado na pesquisa, pois o problema em que as crianças mais utilizaram as notações tinha como resposta 14.

Em síntese, nosso estudo mostrou que as crianças conseguiram realizar interessantes elaborações iniciais relativas à matemática básica por meio da literatura infantil. No entanto, lembramos que as crianças examinadas pertencem a famílias da classe média e que a maioria estuda na mesma escola particular desde o Maternal I.

Mesmo assim, outras razões ainda podem ser evocadas para explicar nossos resultados:

- O tempo de duração de cada sessão (mais ou menos 30 minutos) foi condizente ao tempo de concentração que crianças de cinco anos, em média, apresentam para uma atividade;

- O número de crianças (sete) participantes das sessões foi suficiente para que pudéssemos dar atenção, ouvir todas, incentivá-las com perguntas;

- A história explorada (Branca de Neve e os Sete Anões) é bem familiar às crianças, fazendo com que elas se mantivessem muito envolvidas pelo tema. As crianças sentiram-se desafiadas a buscar soluções e mantiveram-se curiosas até terminar cada sessão;

- Foi mantido, na sala de aula, um clima favorável à troca de idéias e de soluções para que as crianças chegassem aos resultados, levantassem hipóteses, registrassem e transmitissem aos colegas e à pesquisadora o caminho que percorreram para chegar à solução;

- Tivemos, como parâmetros, os resultados de dois estudos-piloto que nos deram subsídios para prever situações que poderiam ocorrer no estudo principal; 
- Tivemos a intenção de considerar a criança como sujeito cognitivo na relação didática, possibilitando-lhe que, além de resolver os problemas propostos, também inventasse problemas para o grupo resolver (BROUSSEAU, 1996; MORGADO, 1993);

- Tivemos razoável domínio na condução das sessões; mas nesta condução a pesquisadora no papel de professora foi, às vezes, demasiadamente indutora, dirigindo as crianças para que chegassem à solução correta dos problemas;

- Os problemas propostos foram cuidadosamente pensados para que não se constituíssem em algo muito distante da experiência provável das crianças estudadas, não só com a história Branca de Neve e os Sete Anões, como especialmente no que se refere às relações aritméticas elementares possíveis de serem trabalhadas pelas crianças;

- Como trabalhamos com relações aritméticas elementares, não tivemos a intenção de introduzir a simbologia matemática escrita como, por exemplo, os sinais de +, -, = (MORGADO, 1993). Porém, valorizamos as notações que as crianças puderam realizar, seus desenhos com escrita de algarismos. E, nesse quadro, deixamos às crianças a possibilidade de elas utilizarem ou não notações para resolver os problemas propostos;

Enfim, as histórias de literatura infantil podem ser exploradas para que elaborações matemáticas aconteçam. Porém, cabe ao professor:

- Analisar previamente a história para que perceba se existe possibilidade de ocorrer o trabalho matemático por meio dela;

- Trabalhar com pequenos grupos;

- Respeitar o tempo de concentração das crianças;

- Considerar os tipos de problemas que podem ser propostos. Por exemplo: os problemas de adição e subtração com parcelas pouco extensas, as comparações qualitativas e correspondências numéricas que utilizamos;

- Considerar que em apenas três sessões, de trinta minutos aproximadamente, conseguimos resultados interessantes com as crianças. Por este motivo, é necessário dosar adequadamente quando trabalhar a matemática por meio da literatura infantil. Mas esta forma de fazer matemática inicial em instituições de Educação Infantil não pode ser considerada a única forma de fazer ali essa iniciação matemática;

- Considerar que na pesquisa fizemos, muitas vezes, uma intervenção indutora marcante das respostas corretas e isto não tem necessidade de 
acontecer. A professora poderá lançar perguntas e não conduzir tanto as crianças para que cheguem necessariamente às respostas corretas;

- Explorar muito a história como literatura para que depois seja realizado o trabalho matemático com ela;

- Ter claro que usar a literatura para trabalhar a matemática não é um pretexto e sim, um meio. Desta maneira, os problemas propostos pelas crianças podem até mudar o curso da história; por exemplo: "Como seria a história se a madrasta tivesse envenenado os anões ao invés da Branca de Neve? E se a Branca de Neve não tivesse comido a maçã envenenada? E se o príncipe não aparecesse para acordar a Branca de Neve?"

Não sendo pretexto, podemos trabalhar com a literatura infantil integrandoa também a outras áreas além da matemática, como seria o caso da exploração e do desenvolvimento da linguagem, do vocabulário e da imaginação infantil.

\section{REFERÊNCIAS}

BROUSSEAU, G. Os diferentes papéis do professor. In: PARRA C.; SAIZ, I. (Orgs.). Didática da matemática: reflexões psicopedagógicas. Tradução: J. A. Llorens. Porto Alegre: Artes Médicas, 1996. p. 48-72.

CAREY, D. The patchwork quilt: a context for problem solving. Arithmetic Teacher, v. 40, n. 4, p.199-203, 1992.

FRANCHI, A. Considerações sobre a teoria dos campos conceituais. In: MACHADO, S. D. (Org.). Educação matemática - uma introdução. São Paulo: Educ, 1999. p.155-196.

KLIMAN, M. Integrating mathematics and literature in the elementary classroom. Arithmetic Teacher, v. 40, n. 6, p. 318-321, 1993.

MORGADO, L. M. de A. O ensino da aritmética: perspectiva construtivista. 1. ed. Coimbra: Livraria Almedina, 1993.

NUNES, T.; BRYANT, P. Crianças fazendo matemática. Tradução: S. Costa. Porto Alegre: Artes Médicas, 1997.

RÊGO, R. G.; SILVA, A. C. Matemática e literatura infantil: um estudo da formação do conceito de multiplicação. In: CONGRESSO BRASILEIRO DE PSICOLOGIA DO DESENVOLVIMENTO, 4., 2003, João Pessoa. Anais... João Pessoa: SBPD/UFPB, 2003. p. 105-106. 
SARAIVA, J. A. Literatura e alfabetização - do plano do choro ao plano da ação. Porto Alegre: Artes Médicas, 2001.

SELVA, A.; BRANDÃO, A. A notação escrita na resolução de problemas por crianças pré-escolares. Psicologia: Teoria e Pesquisa, v. 16, n. 3, p. 241-249, 2000.

SMOLE, K. A matemática na educação infantil. Porto Alegre: Artes Médicas, 1996.

Texto recebido em 19 set. 2004 Texto aprovado em 23 nov. 2004 